\title{
A DEFINIÇÃO DA POLÍTICA DE FORMAÇÃO INICIAL DE PROFESSORES NA UFAC: TERRENO DE IMPASSES, DISPUTAS E LUTAS CONCORRENCIAIS
}

\author{
Tânia Mara Rezende Machado ${ }^{1}$ \\ Elizabeth Miranda de Lima $^{2}$ \\ Lenilda Rêgo Albuquerque de Faria ${ }^{3}$
}

\begin{abstract}
RESUMO
Esse ensaio tem por objetivo descrever e analisar os processos de reformas nos projetos de formação inicial de formação de professores desencadeados na Universidade Federal do Acre no período de 2003 a 2016 . A análise foi realizada com base em referências teóricas que tratam da formação de professores no contexto de reestruturação social, política e cultural do capitalismo e de aprovação da Resolução CNE 02 de julho de 2015, que estabelece novos ordenamentos para a configuração curricular. Nesse contexto, foi construído um movimento inovador de repensar a formação de professores com a incorporação no debate dos movimentos sociais e interlocutores pertencentes às várias unidades acadêmicas. A análise pautou-se na categoria de campo e luta simbólica de Bourdieu (1989) que possibilitou a compreensão das ambivalências e das contradições, bem como, do acirramento das disputas concorrenciais por carga horária, prestígio de área e concepções epistemológicas no terreno da formação de professores.
\end{abstract}

\section{PALAVRAS-CHAVE}

Formação de professores. Reformas. Currículo.

\section{INTRODUÇÃO}

As políticas educacionais têm sido pródigas em operar reformas no campo da formação de professores em consonância com novas finalidades atribuídas a escola no contexto de reestruturação social, política e cultural do capitalismo. Nas duas últimas décadas estas políticas direcionam-se para garantia da democratização do acesso a escolarização da educação básica e infantil, articulando-a as questões da equidade social e do combate à pobreza, pelo discurso da qualidade e maior eficiência da escola como demonstram as pesquisas de Oliveira (2013), Oliveira \&Assunção (2009), Freitas (2014), Libaneo (2012).

Nestas circunstâncias estas reformas produzem impactos diretos na formação e no trabalho do professor. A exigência sobre o êxito da escola e o desempenho do aluno recai sobre o professor, com desdobramentos para a política curricular da formação inicial docente, a qual passa a exigir das instituições formadoras reformas nos projetos pedagógicos curriculares dos cursos de licenciatura, de modo a assegurar as novas orientações reclamadas (impostas) nos processos de regulação e avaliação instituídos.

Na análise de Faria Filho (2010), a ênfase posta na ideia que faz coincidir a reforma

\footnotetext{
${ }^{1}$ Doutora em Educação (PUC-SP, 2010) e Professora da Universidade Federal do Acre, Centro de Educação, Letras e Artes.

${ }^{2}$ Doutora em Educação (PUC-SP, 2002) e Professora da Universidade Federal do Acre, Centro de Educação, Letras e Artes.

${ }^{3}$ Doutora em Educação (USP, 2011) e Professora da Universidade Federal do Acre, Centro de Educação, Letras e Artes.
} 
social via reforma da escola e consequentemente, reforma da formação de professor não se constitui uma ideia nova, antes se caracteriza como um fenômeno cíclico, que remonta aos anos 30 do século XIX, percepção esta, especialmente condensada nos pareceres de Rui Barbosa ao afirmar:

a reforma dos métodos e reforma do mestre: eis a expressão completa, a reforma escolar inteira; eis o progresso todo e, ao mesmo tempo, toda a dificuldade contra a mais endurecida de todas as rotinas - a rotina pedagógica (Apud FARIA FILHO, 2010, p. 16).

É notável a crença de que é possível realizar a reforma social por meio da ação escolar, particularmente à ênfase atribuída ao professor como protagonista e responsável pelo sucesso dessa empreitada. A universidade enquanto espaço formativo não está isenta dessa perspectiva reformista, notadamente, nos projetos curriculares. Assim sendo, no presente ensaio temos por objetivo descrever e analisar os processos de reformas nos projetos de formação inicial de formação de professores desencadeados na Universidade Federal do Acre no período de 2003 a 2016.

A metodologia adotada para a coleta de dados partiu da consulta a fontes documentais como: a legislação educacional que normatiza a organização curricular de formação de professores no Brasil, bem como, o exame de dois projetos curriculares de formação pedagógica comum aos cursos de licenciaturas construídos em diferentes momentos e memórias dos fóruns de debates realizados em prol das reformulações curriculares descritas. Para a análise privilegiamos referências teóricas que tratam do campo da formação de professores na interface com o campo do currículo no contexto de reestruturação social, política e cultural do capitalismo e de aprovação da Resolução CNE 02 de julho de 2015, que estabelece novos ordenamentos para a configuração curricular.

\section{PROJETO DE FORMAÇÃO PEDAGÓGICA COMUM AOS CURSOS DE LICENCIATURA NA UFAC: EMBATES E REDESENHO, EM 2003}

A obrigatoriedade de implantação das Diretrizes Curriculares Nacionais - CNE/CP 01/2002, e as diretrizes curriculares nacionais específicas para cada área da formação de professores demandou à UFAC o enfrentamento de questões no campo da formação docente, como àquelas ligadas à identidade epistemológica dos projetos de curso, a definição de uma carga-horária e a reorganização do currículo das licenciaturas, a relação entre os componentes pedagógicos e os específicos, mas, principalmente, a definição da licenciatura como um projeto pedagógico curricular com identidade própria. 
Essas questões se agravam a considerar a cultura institucional legalista que condiciona a contratação de professores à carga horária letiva dos cursos de graduação, acirrando as discussões e posturas empreendidas na direção de lutas concorrenciais que se materializam aritmeticamente pelo loteamento de horas envolvendo a carga-horária dos cursos na 'grade curricular' com consequências desastrosas para a formação dos futuros professores.

Para além das disputas concorrenciais travadas entre formação específica versus formação pedagógica, o embate entre posturas que buscam reafirmar uma posição hegemônica de valorização e hierarquização de determinadas áreas, em detrimento de outras consideradas historicamente de menor prestígio, algumas questões foram superadas, outras negadas e silenciadas.

A expressão disputas concorrenciais baseia-se na formulação do conceito de campo de Bourdieu (1989), particularmente ao se referir as relações simbólicas e políticas que perpassam as disputas do campo científico ao destacar que:

é enquanto instrumentos estruturados e estruturantes de comunicação e de conhecimento que os sistemas simbólicos cumprem a sua função política de instrumentos de imposição ou de legitimação da dominação que contribuem para assegurar a dominação de uma classe sobre outra (violência simbólica) dando reforço da sua própria força às relações de força que as fundamentam (BOURDIEU, 1989, p. 11).

A partir da publicação da Resolução CNE 01/2002, a Universidade Federal do Acre, protagonizado pelo, à época, Departamento de Educação, desencadeou um processo de debate da formação pedagógica comum aos cursos de licenciaturas, com o propósito de revisar a Resolução CEPEX $N^{\circ}$ 14/87, com o objetivo de redefinir os componentes da área de educação, e simultaneamente, instalaras discussões e reflexões sobre a licenciatura como um projeto de formação de professores, confirmando que:

Entre os extremos da superimposição normativa e da aquiescência, por um lado, e da
resistência ou rebelião por outro, há que estudar em que medida as orientações
consagradas e decretadas são efetivamente reproduzidas e realizadas (LIMA, 2008,
p. 58-59)

Esse processo, provocado por força de lei, mas também, pela compreensão histórica da área de que o formato institucional dado aos cursos de licenciaturas aprofundava a dicotomia entre os dois blocos justapostos de conhecimentos, um que se destinava a formação específica e o outro a formação pedagógica, caracterizando-se em uma (de) formação dual, na qual a identidade do professor continuava subsumida a formação do bacharel.

Para tal foi constituída uma Comissão responsável pela elaboração de um projeto de 
formação pedagógica comum aos cursos da UFAC, estruturado a partir de princípios tais como: a escola e o trabalho pedagógico devem ser objeto privilegiado de investigação e de estudo; os saberes constitutivos da formação e a construção da identidade de professor devem ser desenvolvidos de forma concomitante e com igual importância ao longo do processo formativo; a formação do licenciado deve ter a escola pública como foco central de interesse; e a relação teoria-prática devem se constituir em eixo norteador da formação do licenciado, de modo a assegurar o desenvolvimento de uma postura investigativa e problematizadora da realidade escolar.

Com base nesses princípios e com o propósito de romper com a ideia de que as disciplinas têm um fim em si mesmo, o projeto propôs a organização dos componentes curriculares em núcleos aglutinadores - Instituição escolar e Trabalho docente, Investigação da prática pedagógica e Desenvolvimento profissional - de modo a potencializar o diálogo entre as disciplinas de caráterteórico, práticoe de estágio. Destacamos que a concepção de prática sob a qual se configura essa proposta distancia-se do entendimento de prática de ensino visto como um momento de treinamento ou como de aplicação de modelos aprendidos, e se aproxima de uma concepção teórico-prática, organicamente vinculada à realidade escolar, visando à articulação entre os elementos da formação inicial e a ambientação do licenciando com o seu campo de trabalho que é a escola.

A partir dessa compreensão, o aprendiz de professor ao vivenciar as escolas como espaços de formação e desenvolvimento da prática docente terá a oportunidade de problematizar as teorias implícitas, valores e crenças pessoais, incompatíveis com a realidade escolar e o desenvolvimento profissional. Sendo necessário "desaprender e reaprender", substituindo a imagem espontânea do ensino, concebido como algo essencialmente simples, para o qual basta um bom conhecimento da matéria, algo de prático e alguns complementos psicopedagógicos.

A partir desse entendimento o componente estágio supervisionado foi proposto de forma articulada com os professores da área de educação, dos departamentos das áreas específicas, em colaboração com os professores regentes das redes de educação do estado e do município. Assim o estágio é considerado como espaço formativo privilegiado no qual o licenciando mobiliza saberes profissionais os problematizando e os ressignificando em situação prática.

A proposta produzida pela Comissão resultou no Projeto de Formação Pedagógica Comum para os Cursos de Licenciatura da UFAC/2003 e foi encaminhada as instâncias de deliberação superior da universidade, a começar pelo Conselho de Ensino, Pesquisa e 
Extensão - CEPEX e, posteriormente, ao Conselho Universitário - CONSU para apreciação e aprovação. O longo tempo decorrido entre a discussão do parecer do relator, o pedido de vistas demandado por um dos conselheiros e sua aprovação final revelou-se como indicativo da falta de prioridade atribuída à formação de professores no interior da universidade, como também, a compreensão de que a formação docente se constitui em espaço de contradições e ambivalências internas que, em se tratando de uma política de formação de professores, demanda a construção de um relativo consenso em termos de linhas gerais de uma política de formação de professores.

As discussões nessas instâncias foram caracterizadas por dificuldades dos interlocutores em entender a dimensão do trabalho pedagógico como mediação da formação docente, a licenciatura como um projeto interdisciplinar, a compreensão da prática como componente curricular que correspondesse a construção de um projeto formativo que transcendesse o mera discussão de distribuição de carga horária entre as unidade acadêmicas.

Desse processo, resultou uma política institucional que não foi capaz de superar as dicotomias que perpassam a área da formação de professores, uma vez que os princípios e concepções que orientavam a proposta original foram desconsiderados no seu conjunto, produzindo meros arranjos pontuais nas ementas que não garantiam uma articulação interna na configuração dos Projetos Pedagógicos Curriculares dos Cursos. Nesse contexto, a primeira vista, as proposições que se configuraram como aspectos inovadores da Resolução $\mathrm{n}^{\circ}$ 01/2002, incorporados na proposta apresentada, foram esvaziadas em seu sentido políticoformativo e não se materializaram na prática.

\section{A PROPOSTA CURRICULAR DE FORMAÇÃO DE PROFESSORES, EM 2016: NOVOS EMBATES, DESAFIOS E PERSPECTIVAS}

Transcorrida mais de uma década, dos fatos descritos na seção anterior, novas configurações são produzidas no campo da formação de professores estabelecidas na Resolução CNE/CP de julho de 02 de 2015, que diferentemente da Resolução CNE/CP 01/2002, aglutinou as diretrizes da formação inicial a formação continuada, os cursos de formação pedagógica e de segunda licenciatura, estabelecendo relações com o disposto no Plano Nacional de Educação, bem como, na Base Nacional Comum Curricular (ainda em análise pelo $\mathrm{CNE}$ ) determinando novos caminhos para o redesenho dos projetos curriculares dos cursos de licenciatura. 
Nesse cenário, antigas questões são retomadas colocando a necessidade de se conferir aos projetos curriculares uma organicidade propiciada pela articulação entre os sistemas públicos de educação básica, os fóruns estaduais e municipais de formação docente e os movimentos sociais organizados. Nesse sentido, impulsionado por uma nova legislação, um grupo de professores da área de educação volta a exigir da administração superior da Universidade uma postura de debate amplo e interdisciplinar que promovesse uma compreensão da reforma curricular dos cursos de licenciaturas para além de um mero rearranjo da 'grade curricular', mas de assumir o sentido maior da Resolução CNE/CP 02/2015 que aponta na direção de que pensar a identidade própria de um curso de licenciatura envolve a definição de uma política institucional orgânica que se configure entre a instituição formadora e as escolas de educação básica, em sintonia com os diferentes grupos sociais, sem, contudo, deixar de ter atenção aos riscos de cacofonia, observando-se os princípios dispostos no Art. 3, § 06:

O projeto de formação deve ser elaborado e desenvolvido por meio da articulação
entre a instituição de educação superior e o sistema de educação básica envolvendo a
consolidação de fóruns estaduais e distrital permanentes de apoio a formação
docente, em regime de colaboração e deve contemplar:
I - sólida formação teórica e interdisciplinar dos profissionais;
II - a inserção dos estudantes de licenciatura nas instituiçães de educação básica da
rede pública de ensino, espaço privilegiado da práxis docente;
III - o contexto educacional da região onde será desenvolvida;
IV - as atividades de socialização e a avaliação de seus impactos nesses contextos;
V - a ampliação e o aperfeiçamento do uso da Língua Portuguesa e da capacidade
comunicativa, oral e escrita, como elementos fundamentais da formação dos
professores, e da aprendizagem da Língua Brasileira de Sinais (Libras);
VI - as questões socioambientais, éticas, estéticas e relativas à diversidade étnico-
racial de gênero, sexual, religiosa, de faixa geracional e sociocultural como
princípios de equidade. (Resolução CNE/CP 02/2015)

Assim, a formação de professores volta a ser objeto de acirrados debates e disputas no plano do currículo e das concepções epistemológicas da formação. Nessa ambiência foi constituída uma "Comissão responsável pela elaboração de adequações às ementas das disciplinas pedagógicas comuns às licenciaturas", que decidiu como metodologia de trabalho a organização de sessões temáticas voltadas para a análise dos objetos elencados no Art. 13, § $2^{\circ}$, da Resolução CNE/CP - 2/2015, a qual determina que os cursos de formação de professores deverão garantir em seus currículos conteúdos relativos aos direitos humanos, diversidades étnico-racial, de gênero, sexual, religiosa, de faixa geracional, Língua Brasileira de Sinais (Libras), educação especial e direitos educacionais de adolescentes e jovens em cumprimento de medidas sócio educativas. 
A metodologia adotada para o desenvolvimento do trabalho da Comissão primou pelo aprofundamento das temáticas por meio do diálogo com professores da instituição que estudam, pesquisam e/ou militam nos conteúdos mencionados, além de convidados externos vinculados aos movimentos sociais organizados - Fórum da diversidade étnico-racial, representantes de professoresindígenas, Secretaria da promoção da igualdade racial, UNIAFRO, representantes da Secretaria Municipal e Estadual de Educação, da Escola Dom Bosco e da UFAC do Núcleo de Assistência à Inclusão.

Ao eleger essa metodologia de trabalho a Comissão entendia a partir de Bourdieu (1989) e Arroyo (2011) quão disputado é o campo curricular e rememorava também Aplle (1999) ao afirmar que:

O currículo nunca é apenas um conjunto neutro de conhecimentos, que de algum modo aparece nos textos e nas salas de aula de uma nação. Ele é sempre parte de uma tradição seletiva, resultado da seleção de alguém, da visão de algum grupo acerca do que seja conhecimento legítimo (APLLE, 1999, p. 59).

Por reconhecer as relações de poder que permeiam a legitimação de currículos, o sentido do diálogo com os diversos segmentos foi o de ampliar o debate, bem como, o acolhimento e sistematização das proposições advindas desses grupos e sujeitos como elementos balizadores do redesenho da proposta de formação de professores ora apresentada.

As sessões temáticas aconteceram no período de abril a junho de 2016, organizadas em mesas de debates que resultaram em importantes contribuições para o aprofundamento dos temas - educação e direitos humanos, diversidade étnico-racial, questões de gênero e faixa geracional, sexualidade, educação inclusiva. Nesse sentido, o diálogo oportunizou a retomada dos marcos legais e o entendimento da especificidade epistemológica dos objetos abordados nos debates. Assim, as discussões nos desafiaram a pensar um redesenho curricular de formação de professores em uma perspectiva interdisciplinar, inclusiva, participativa e de respeito à diversidade. Esse movimento propiciou a compreensão de que os itinerários de formação de professores para educação básica precisam considerar o espaço escolar como lócus de humanização, razão pela qual se faz imprescindível contemplar nos currículos da formação inicial as temáticas contidas no parágrafo em estudo.

A abordagem teórico-metodológica da temática educação e direitos humanos se fundamentou em uma perspectiva crítica de educação que transcende o reconhecimento dos direitos políticos, civis e sociais, materializando-se na transformação dos valores, das concepções e das práticas de convivências humanas, entendendo-se que a formação dos 
indivíduos se dá mediante a apropriação da cultura, condição para que se reconheçam como humanos e como sujeitos de direitos, relacionados à sua natureza humana.

Nesse sentido, em uma sociedade profundamente marcada pela desigualdade, a educação tem um papel imprescindível na formação política e cidadã das pessoas de modo a contribuir na prática social dos indivíduos no enfrentamento dos obstáculos postos a consecução dos direitos e agressões à dignidade humana.

No tocante as análises sobre as questões étnico-raciais o entendimento de que a presença da Lei 11.645/2008 nos currículos dos cursos universitários por si só não garante a alteração das práticas de preconceito e discriminação racial, queestão profundamente impregnadas nas práticas institucionais, sob a forma de um racismo institucional. Desse modo, o conceito de desigualdade racial se constitui como elemento central para a compreensão dos mecanismos produtores desse processo de assimetria, aprofundado por outras formas de desigualdade como a econômica, a social e cultural, praticadas por grupos sociais dominantes, enquanto outros são marginalizados. Assim, a luta contra a desigualdade tem como ponto de apoio a lei, bem como as exigências por políticas públicas de promoção das condições de igualdade sem mascarar as diferenças, e nessa direção apontamos como significativo o investimento em políticas institucionais de formação de professores que os coloque em condições de trabalharem com essas temáticas.

Ainda como resultantes dessas análises concernentes as formas de exclusão ou de recusa ao diferente se sobressai a questão dos povos indígenas, principalmente àquelas relacionadas a cultura, a identidade e as relações com a educação formal. Assim, destacou-se a perspectiva da interculturalidade como necessária para o diálogo entre saberes das populações tradicionais e a cultura acadêmica, construindo as possibilidades de por em questão os multicolonialismos. Assim, como forma de conferir visibilidade as culturas indígenas nos projetos curriculares foram apontadas a necessidade da incorporação de categorias como: tradição e ancestralidade, especificidades linguísticas, formas de comunicação e de produção de conhecimentos de cada grupo étnico, que possibilitem a problematização de estereótipos presentes nas representações dos professores e da comunidade escolar.

Também relacionadas às questões da educação inclusiva destacou-se que apesar de algumas conquistas no plano legal permanece o desafio de assegurar o direito educacional para todos, mediante a garantia da aprendizagem aos alunos incluídos, a adequação das escolas as especificidades dos alunos (acessibilidade). Observou-se que nesse momento de reformulação dos projetos curriculares dos cursos de formação inicial de professores cabe 
assegurar a presença de componentes curriculares formativos tais como Libras, educação especial, estágio e atividades práticas na área, além de questões mais específicas do processo de ensino-aprendizagem como a produção de materiais didáticos e metodologias de ensino.

\section{CONCLUSÃO}

Em que pese o fato do momento ser favorável as ações de reformulações curriculares, impulsionadas pela publicação das novas Diretrizes de Formação de Professores e pelas demandas sociais, as contradições vivenciadas internamente entre alguns professores da área de Educação e a Pró-Reitoria de Graduação/UFAC, o projeto foi natimorto. Isto é, tendo sido encaminhado oficialmente para apreciação interna pela área de educação a proposta foi peremptoriamente negada sob a argumentação de extemporalidade do prazo estabelecido pela portaria que institui a comissão responsável pela proposta. Sendo assim, a oportunidade do exame e do debate da proposta construída coletivamente foi negada, deixando transparecer o corporativismo cego que reproduz o conservadorismo da universidade e que compromete avanços e inviabilizam projetos curriculares inovadores.

Nesse novo contexto de reforma curricular, a dificuldade da instancia responsável pela definição da política de graduação em definir, em linhas gerais, um Projeto de Formação para os cursos de bacharelado e licenciaturas produz um efeito potencializador das situações de mal estar, conflitos e esgarçamento das relações acadêmico profissionais. Soma-se a essa situação uma lógica produtivista que gera entre seus agentes acadêmicos a impaciência para o debate, indisposição para o diálogo, a intolerância com o pensamento divergente tendendo a resultar no enfraquecimento das instancias colegiadas na contramão da especificidade da universidade.

Como aprendizado ético, político e pedagógico dessa experiência resultou na compreensão de que a superação da dualidade histórico-cultural da formação de professores em sua base epistemológica e pedagógica implica em alterações das estruturas feudais em que nos situamos academicamente, encarcerados nos limites de nossas unidades e disciplinas. No entanto, como efetuar esse movimento em um cenário em que o contexto histórico-social tem direção e sentidos contrários? Em uma ambiência institucional que produz subjetividades que tendem a acirrar competitividades, excluindo a solidariedade de classe e sufocando o trabalho coletivo e colaborativo?

Sem ter a intenção de responder a essas problematizações, sinalizamos na direção de que é necessário escapar/resistir aos modismos que perpassam o campo educacional - mística da competência e da inovação, o fetiche do profissionalismo, a polissemia da prática 
pedagógica. Assim, construir itinerários formativos requer intencionalidade, trabalho árduo, direção, diálogo e parceria. Reconhecemos que quaisquer que sejam nossas áreas de atuação, disciplinas e/ou nível de ensino, o fato é que na medida em que fazemos parte do sistema escolar somos todos "professores de escola".

THE DEFINITION OF THE INDUCTION TRAINING POLICY FOR PROFESSORS AT THE FEDERAL UNIVERSITY OF ACRE (UFAC): A GROUND FOR DEADLOCKS, DISPUTES AND COMPETITION

\begin{abstract}
This essay seeks to describe and analyse the reorganisation processes in the projects of induction training for lecturing staff developed at the Federal University of Acre between 2003 and 2016. The analysis was conducted by drawing upon theoretical references on the training of lecturers in the context of the social, political and cultural restructuration of capitalism concomitant to the legislative Resolution CNE 02 of 2 July 2015, which establishes new guidelines as to the curricular configuration. In this context, an innovative strategy was constructed around the idea of rethinking lecturing staff training by including in the debate social movements and interlocutors connected to the various academic units. The analysis was based on Bourdieu's categories of field and symbolic struggle (BOURDIEU, 1989), which allowed for the understanding of ambivalences and contradictions in the context of lecturing staff training, alongside the exasperation of disputes over hourly workloads, academic reputation and epistemological conceptions.
\end{abstract}

\title{
KEYWORDS
}

Lecturer training. Reforms. Curriculum.

\section{REFERÊNCIAS}

APPLE, M. W. A política de conhecimento oficial: faz sentido a idéia de um currículo nacional? In: MOREIRA, A. F. B.; SILVA, T. T. Currículo, cultura e sociedade. 3. ed., São Paulo: Cortez, 1999, pp. 59-92.

ARROYO, M. G. Currículo, território em disputa. Petrópolis-RJ: Vozes, 2011.

BOURDIEU, P. O poder simbólico. Trad. Fernando Tomaz. Rio de Janeiro-RJ: Bertrand Brasil, 1989.

BRASIL. Resolução CNE/CP no 01 de fevereiro de 2002. Institui Diretrizes Nacionais para a formação de professores da educação básica em nível superior, curso de licenciatura, de graduação plena.

BRASIL. Resolução $\mathbf{n}^{\circ} 02$ de 01 de julho de 2015. Define as Diretrizes Curriculares Nacionais para a formação inicial em nível superior (cursos de licenciatura, cursos de formação pedagógica para graduados e cursos de segunda licenciatura) e para a formação continuada.

BRASIL, Ministério da Cultura. Presidência da República. Lei no 11.645, de 10 de março de 2008. Altera a Lei no 9.394, de 20 de dezembro de 1996, modificada pela Lei no 10.639, de 9 de janeiro de 2003, que estabelece as diretrizes e bases da educação nacional, para incluir no currículo oficial da rede de ensino a obrigatoriedade da temática "História e Cultura AfroBrasileira e Indígena”. Brasília: 2008. Disponível em: http://www.planalto.gov.br/ccivil_03/_ato2007-2010/2008/lei/111645.htm. Acessado em 27 de dezembro de 2016.

FARIA FILHO, L. M.; NASCIMENTO, C. V.; SANTOS, M. L. Reformas educacionais no Brasil: democratização qualidade da escola pública. Belo Horizonte, MG: Mazza edições, 2010. 
FREITAS, L. C. Os reformadores empresariais da educação e a disputa pelo controle do processo pedagógico na escola. In: Educação e Sociedade. Campinas, v.35, n.129, out/2010, pp.1085-1114.

LIBANEO, J. C. Internacionalização das políticas educacionais e políticas para a escola: elementos para uma análise pedagógico-política de orientações curriculares para o ensino fundamental. In: TOMMASIELLO. M. G. C. [et al.].- Didática e prática de ensino na realidade escolar contemporânea: constatações, análises e proposições. Araraquara (SP): Junqueira \& Marin, 2012.

LIMA, L. C. Produção e reprodução de regras: normativismo e infidelidade normativa. In: LIMA, L. C. A escola como organização educativa: uma abordagem sociológica. São Paulo: Cortez, 2008, pp. 57-69.

OLIVEIRA, D. A. Política educativa, crise da escola e a promoção de justiça social. In: FERREIRA, E. B. e ANDRADE, O. (Orgs.). Crise da escola e políticas educativas. 2. Ed., Belo Horizonte (MG): Autentica Editora, 2013.

OLIVEIRA, D. A. \& ASSUNÇÃO, A. A. Intensificação do trabalho e saúde dos professores. In: Educação e Sociedade, v.30, n.107, 2009, pp. 349-372.

UNIVERSIDADE FEDERAL DO ACRE - UFAC. Conselho de Ensino, Pesquisa e Extensão. Resolução n. 14, de 18 de agosto de 1987. Dispõe sobre a proposta de regulamentação da formação pedagógica, para os cursos de licenciatura. Rio Branco/AC: UFAC/CEPEX, 1987.

Universidade Federal do Acre. Departamento de Educação. Projeto de formação Pedagógica Comum para os Cursos de Licenciatura da UFAC. Rio Branco, 2003. 